\title{
Randomised controlled trial of rehabilitation in chronic respiratory disability
}

\author{
A E COCKCROFT, M J SAUNDERS, AND G BERRY
}

From the Pneumoconiosis Unit, Llandough Hospital, Penarth, South Glamorgan

ABSTRACT A randomised controlled study of the effects of exercise training in 39 patients with chronic respiratory disability was performed. Exercise training began with six weeks in a rehabilitation centre and was continued at home. The original control group attended the rehabilitation centre after the controlled part of the study. The treated group experienced subjective benefit from rehabilitation. The 12-minute walking distance increased on average from $523 \mathrm{~m}$ to $643 \mathrm{~m}$ in the treatment group and from $564 \mathrm{~m}$ to $607 \mathrm{~m}$ in the control group. The treatment effect of $77 \mathrm{~m}$ (SE $33 \mathrm{~m}$ ) was significant at the $5 \%$ level. Treadmill exercise performance changed little and resting lung function was unaltered after rehabilitation. The treatment group maintained most of their improvement seven months later and the original control subjects improved after their rehabilitation. The study confirms the beneficial effects of exercise training in the chronically breathless and it suggests that the 12-minute walking distance is a useful index of changes in everyday exercise tolerance.

Cardiorespiratory disorders in the older age groups are a large and increasing cause of disability in the United Kingdom. ${ }^{1}$ A number of investigators have studied the effects of exercise training in people with chronic respiratory disability. ${ }^{2-18}$ There is general agreement that measurable improvement can be produced by various types of exercises but only a few of the studies have included a satisfactory control group. ${ }^{14-16}$ We carried out a randomised controlled study of the effects of exercise training in men with chronic respiratory disability. After the first part of the study, the original control group were also given exercise training and were followed up afterwards.

\section{Methods}

We studied 39 outpatients. Most of them were ex-coalworkers with varying degrees of coalworkers' pneumoconiosis as well as chronic obstructive airways disease. All of them were breathless on exertion but there was no upper limit of forced expiratory volume in one second $\left(\mathrm{FEV}_{1}\right)$ for entry into the study. We excluded men over the age of 70 years, those with other disabling conditions such as severe arthritis, and those who required domiciliary oxygen. Each man was told when he entered the study

Address for reprint requests: Dr AE Cockcroft, MRC Pneumoconiosis Unit, Llandough Hospital, Penarth, South Glamorgan CF6 1XW, Wales. that exercises might help him and that he would go to a rehabilitation centre either immediately or after a few months. Men were admitted into the study during the period from January to March 1979.

After the initial assessment, the men were allocated to the treatment or control group. The first 20 were allocated entirely randomly and the remaining 19 by a method known as "minimisation" which ensured an even spread of certain variables between the groups. ${ }^{19}$ The variables chosen were smoking habits, age, and performance in a 12-minute walking test.

Immediately after entry, the treatment group spent six weeks in a rehabilitation centre where they undertook graduated exercise training. They worked in the gymnasium including exercises on bicycle ergometers and rowing machines; they swam and exercised in the swimming pool; and they took twice daily walks over increasing distances of up to two miles. Each man noted his progress on a personal record card. On discharge, they were given verbal and written instructions to continue with simple exercises at home. Recommended home exercises included stair climbing and level walking, ${ }^{15}$ and they were given diary sheets to fill in. The control group was given no special advice to exercise. After four months, when their period as controls was over, they went to the rehabilitation centre for six weeks and were instructed to exercise at home afterwards.

We assessed all the men at entry, at two months, and at four months. The original treatment group 
was assessed again after a further four to five months of exercises at home, and the original control group again after their stay in the rehabilitation centre. On each occasion we measured the 12-minute walking distance in a covered hospital corridor, using the method of McGavin et al. ${ }^{20}$ The men walked both in the morning and in the afternoon on each visit. Morning and afternoon walking distances were very similar so we used the mean value for our analyses. We measured $\mathrm{FEV}_{1}$ and forced vital capacity (FVC) using a low resistance digital spirometer. ${ }^{21}$ On the morning of the first three assessments the men performed a progressive treadmill exercise. The treadmill speed was around $3 \mathrm{kph}$ and the incline was increased by $1.5 \%$ every minute. The exercise was stopped after 10 minutes or sooner if the man could do no more. During the exercise we measured cardiac frequency, minute ventilation, and mixed expired oxygen and carbon dioxide concentrations. Oxygen uptake was calculated from ventilation and oxygen extraction. The method of exercise testing used has been described previously. ${ }^{22}$ The men were weighed on each visit and had a clinical interview, always with the same physician. The physician was aware of the study group of each man but the operators for the tests were kept in ignorance of this.

The effects of treatment were assessed by comparing the mean change of a variable in the treatment group with the mean change in the control group after taking account of the effects of smoking habits, age and initial walking distance, the variables used for matching in the study design, by covariance analysis.

\section{Results}

Five men failed to complete the controlled study. Four of these were in the control group-two were unable to undertake the assessments because of a deterioration in their condition, one suffered a "stroke," and one went on an unexpected trip abroad. One man in the treatment group had to leave the rehabilitation centre because of domestic problems. Details of the 34 men who completed the study are

Table 1 Details of the subjects at the first assessment (mean values \pm standard deviation)

\begin{tabular}{|c|c|c|}
\hline Details & Treatment group & Control group \\
\hline $\begin{array}{l}\text { Number } \\
\text { Smoking habits: smokers } \\
\text { ex or non-smokers } \\
\text { Mean age (yr) } \\
\text { Mean FEV }(1) \\
\text { Mean FVC (1) } \\
\text { Mean weight (kg) } \\
\text { Mean } 12-\text { minute walking } \\
\text { distance (m) }\end{array}$ & 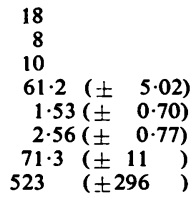 & $\begin{array}{l}16 \\
7 \\
9 \\
60 \cdot 2( \pm 4 \cdot 72) \\
1 \cdot 32( \pm 0 \cdot 44) \\
2 \cdot 56( \pm 0 \cdot 86) \\
71 \cdot 1 \quad( \pm 8 \cdot 9) \\
564 \quad( \pm 221)\end{array}$ \\
\hline
\end{tabular}

shown in table 1 . There were no important differences between the groups at the beginning of the study.

The treatment group experienced subjective benefit from rehabilitation (table 2). After two months, the control subjects nearly all felt the same as before, whereas most of the treatment group felt generally better and thought they could walk further. About half of them said they felt less breathless or had less cough or both, and about one-third reported a reduced sputum volume.

Of the objective measurements, the 12-minute walking distance was the most sensitive index of changes after rehabilitation. The distance walked increased, on average, by $120 \mathrm{~m}$ (SD $119 \mathrm{~m}$ ) in the treatment group and $43 \mathrm{~m}$ (SD $111 \mathrm{~m}$ ) in the control group. Thus the treatment group had an advantage of $77 \mathrm{~m}$ (Standard Error $33 \mathrm{~m} ; \mathrm{p}<0.05$ ). The changes in 12-minute walking distance and measurements during treadmill exercise at two months are summarised in table 3.

We obtained submaximal treadmill exercise results on most of the men and about half reached their maximum exercise tolerance within 10 minutes. There were no significant differences between the groups in measurements during the submaximal exercise before and after rehabilitation. In those who reached maximum levels, the only difference between the groups was in maximum oxygen uptake, which increased significantly in the treatment group compared with the controls $(p<0.05)$. The figure shows the mean increases in 12-minute walking distance in the two groups during the whole study. By four months the difference between the increases was no longer statistically significant. This was the result of continuing improvement in the control group. The original treatment group maintained most of their improvement seven months after their stay in the rehabilitation centre. The original controls improved further after their rehabilitation to a mean walking distance of $695 \mathrm{~m}$. Overall, the maximum increase in mean walking distance was $120 \mathrm{~m}$ in the original treatment group and $154 \mathrm{~m}$ in the original control group.

At two months, there were significantly more men in the treatment group than in the control group who increased their walking distance by $100 \mathrm{~m}$ or more

Table 2 Subjective changes after rehabilitation

\begin{tabular}{lll}
\hline & \multicolumn{2}{l}{ Number experiencing improvement } \\
\cline { 2 - 3 } & Treatment group (18) & Control group (16) \\
\hline General well-being & 16 & 0 \\
Walking ability & 16 & 0 \\
Breathlessness & 9 & $\mathrm{i}$ \\
Cough & 8 & 1 \\
Sputum & 6 & 0 \\
\hline
\end{tabular}


Table 3 Changes in exercise performance after two months

\begin{tabular}{|c|c|c|c|c|c|c|c|c|}
\hline & & $\begin{array}{l}12 M D \\
(\mathrm{~m})\end{array}$ & $\begin{array}{l}\mathrm{nO}_{2}(\mathrm{st}) \\
\left(\mathrm{mmol}_{\left.\mathrm{min}^{-1}\right)}\right.\end{array}$ & $\begin{array}{l}\dot{V} e(s t) \\
\left(I \min ^{-1}\right)\end{array}$ & $\begin{array}{l}\dot{V} e_{45} \\
\left(l \min ^{-1}\right)\end{array}$ & $\begin{array}{l}F c_{45} \\
\left(\text { beats } \text { min }^{-1}\right)\end{array}$ & $\begin{array}{l}\dot{V} e(\max ) \\
\left(l \min ^{-1}\right)\end{array}$ & 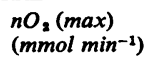 \\
\hline $\begin{array}{l}\text { Treatment } \\
\text { group }\end{array}$ & $\begin{array}{l}\text { At start } \\
\text { After two months } \\
\text { Change }\end{array}$ & $\begin{array}{c}523 \\
643 \\
+120 \\
p<0.05\end{array}$ & $\begin{array}{r}40.6 \\
41.9 \\
+\quad 1.3\end{array}$ & $\begin{array}{r}31 \cdot 3 \\
30 \cdot 7 \\
-\quad 0 \cdot 6\end{array}$ & $\begin{array}{r}30 \cdot 4 \\
28 \cdot 7 \\
-\quad 1 \cdot 7\end{array}$ & $\begin{array}{r}99 \\
97.5 \\
-\quad 1.5\end{array}$ & $\begin{array}{r}35 \cdot 5 \\
37 \cdot 6 \\
+\quad 2.1\end{array}$ & $\begin{array}{r}42.0 \\
45.8 \\
+\quad 3.8\end{array}$ \\
\hline $\begin{array}{l}\text { Control } \\
\text { group }\end{array}$ & $\begin{array}{l}\text { At start } \\
\text { After two months } \\
\text { Change }\end{array}$ & $\begin{array}{r}564 \\
607 \\
+\quad 43\end{array}$ & $\begin{array}{c}42.6 \\
39.3 \\
-\quad 3.3 \\
p<0.05\end{array}$ & $\begin{array}{r}30.9 \\
28 \cdot 7 \\
-\quad 2 \cdot 2\end{array}$ & $\begin{array}{r}29 \cdot 0 \\
28 \cdot 7 \\
-\quad 0 \cdot 3\end{array}$ & $\begin{array}{r}103 \\
97 \cdot 5 \\
-\quad 5 \cdot 5\end{array}$ & $\begin{array}{c}33.5 \\
31.5 \\
-2.0 \\
p<0.05\end{array}$ & $\begin{array}{c}47 \cdot 1 \\
42 \cdot 2 \\
-4.9 \\
p<0.05\end{array}$ \\
\hline $\begin{array}{l}\text { Treatment } \\
\text { effect }\end{array}$ & & $\begin{array}{l}+77 \\
p<0.05\end{array}$ & +4.6 & +1.6 & -1.4 & +4.0 & $+4 \cdot 1$ & $\begin{array}{l}+8.7 \\
p<0.05\end{array}$ \\
\hline
\end{tabular}

$12 \mathrm{MD}=12$-minute walking distance (18 treated, 16 controls); no $\mathrm{O}_{2}(\mathrm{st})=$ oxygen uptake at given treadmill workload (17 treated, 14 controls); $\dot{V e}(s t)=$ ventilation at given treadmill workload (17 treated, 14 controls); $\dot{V e}_{45}=$ ventilation at no $\mathrm{O}_{2}$ of 45 mmol min-1 (13 treated, 11 controls); $\mathrm{Fc}_{45}=$ cardiac frequency at $\mathrm{nO}_{2}$ of $45 \mathrm{mmol} \mathrm{min}{ }^{-1}$ (12 treated, 10 controls); $\dot{\mathrm{Ve}}(\mathrm{max})=$ maximum ventilation (10 treated, 8 controls); $\mathrm{nO}_{2}$ $(\max )=$ maximunı oxygen uptake (10 treated, 8 controls). To convert n $\mathrm{O}_{2}$ in mmol $\mathrm{min}^{-1}$ to $1 \mathrm{~min}^{-1}$ divide by 45 .

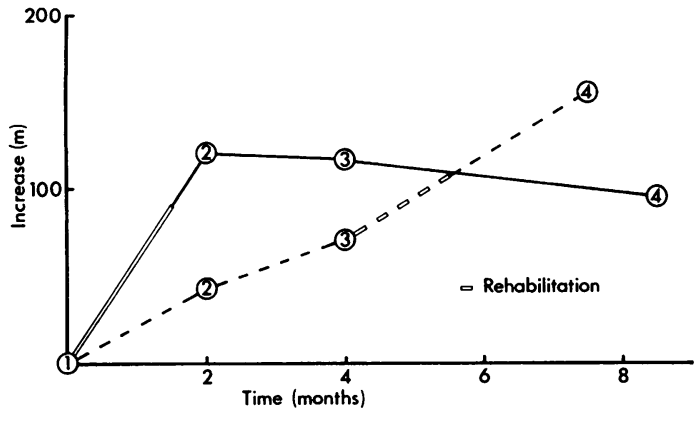

Figure Increases in mean 12-minute walking distance during the study. The solid lines represent the treatment group and the dashed lines the control group. The figures in circles are the assessments made of each group.

( $p=0.037$ by Fisher's exact test, table 4$)$. By the end of the study, the groups had similar numbers who had improved by this amount.

$\mathrm{FEV}_{1}$ and weight did not change in either group during the study. FVC increased slightly in both groups. Neither group changed its smoking habits, although all were advised to stop smoking.

\section{Discussion}

The results from our study are broadly in agreement with previous studies on exercise training. We found marked subjective benefit and measurable objective

Table 4 Number of men who increased their 12-minute walking distance by $100 \mathrm{~m}$ or more

\begin{tabular}{lcc}
\hline & Treatment group & Control group \\
\hline $\begin{array}{l}\text { Between first and second } \\
\text { assessment (two months) }\end{array}$ & $11 / 18$ & $4 / 16$ \\
$\begin{array}{l}\text { Between first and fourth } \\
\text { assessment (approximately } \\
\text { nine months) }\end{array}$ & $7 / 15$ & $10 / 15$ \\
\hline
\end{tabular}

benefit in the treated group compared with a control group. There were no changes in resting lung function. We found the 12-minute walking distance to be an acceptable, simple, and sensitive index of improvement, in agreement with McGavin et al. ${ }^{15}$ Self-paced walking tests have the advantage that almost any breathless patient can perform them, ${ }^{23}$ and they probably reflect ability to perform everyday activities more closely than the more complex exercise tests.

Some authors have reported reduced ventilation at standard workloads ${ }^{2} 3611$ or reduced cardiac frequency during exercise $e^{2-4912}$ after rehabilitation. The details of reported changes induced by exercise training vary considerably perhaps because of the different degree of disability of the patients, different training and testing methods, and different lengths of follow-up. We found no differences between our groups on submaximal exercise after rehabilitation, but an increased maximum oxygen uptake in the treatment group compared with the controls.

We were encouraged by the finding that our original treatment group maintained most of their improvement seven months after their rehabilitation course, but it must be remembered that at this stage there was no longer a control group for comparison. The gradual improvement in the controls before rehabilitation was interesting and possibly the result of becoming more active in preparation for their stay in the rehabilitation centre. After their rehabilitation they improved further and in fact their overall improvement was greater than that of the original treatment group.

The rehabilitation programme reported here was relatively cheap in terms of medical personnel time and accommodation costs compared with a stay in an acute general hospital. It may be possible to reduce the period spent in the rehabilitation centre without loss of effectiveness. We hope that this and other studies indicating the beneficial effects of exercise 
training may encourage more use of rehabilitation in patients with chronic respiratory disability who form a large and increasing section of our society.

We thank the staff of the Talygarn Rehabilitation Centre near Llantrisant, Mid Glamorgan, for their enthusiastic help and the men whose willing cooperation made the study possible.

\section{References}

1 Taylor D. Physical impairment: social handicap. London: Office of Health Economics, 1977.

2 Pierce AK, Taylor HF, Archer RK, Miller WF. Responses to exercise training in patients with emphysema. Arch Intern Med 1964; 113: 28-36.

3 Pierce AK, Paez PN, Miller WF. Exercise training with the aid of a portable oxygen supply in patients with emphysema. Am Rev Respir Dis 1965;91 : 653-9.

4 Paez PN, Phillipson EA, Masangkay M, Sproule BJ. The physiologic basis of training patients with emphysema. Am Rev Respir Dis 1967; 95: 944-53.

5 Ambrus L, Thal SH, Weinstein SB, Warnecke J. Chronic obstructive pulmonary emphysema. Is exercise beneficial ? Calif Med 1967; 106: 354-8.

6 Christie D. Physical training in chronic obstructive lung disease. $\mathrm{Br}$ Med J 1968; 2: 150-1.

7 Woolf CR, Suero JT. Alterations in lung mechanics and gas exchange following training in chronic obstructive lung disease. Dis Chest 1969; 55: 37-44.

8 Petty TL, Nett LM, Finigan MM, Brink GA, Corsello PR. A comprehensive care program for chronic airway obstruction. Methods and preliminary evaluation of symptomatic and functional improvement. Ann Intern Med 1969; 70: 1109-20.

9 Bass H, Whitcomb JF, Forman R. Exercise training: therapy for patients with chronic obstructive pulmonary disease. Chest 1970; 57: 116-21.

10 Nicholas JJ, Gilbert R, Gabe R, Auchincloss JH. Evaluation of an exercise therapy program for patients with chronic obstructive pulmonary disease. Am Rev Respir Dis: 1970; 102 : 1-9.
11 Vyas MN, Banister EW, Morton JW, Grzybowski S. Response to exercise in patients with chronic airway obstruction. 1 Effects of exercise training. Am Rev Respir Dis 1971; 103: 390-400.

12 Holten $\mathrm{K}$. Training effect in patients with severe ventilatory failure. ScandJ Respir Dis 1972;53: 65-76.

13 Brundin A. Physical training in severe chronic obstructive lung disease. Parts I and II. Scand J Respir Dis 1974; 55: 25-36, 37-46.

14 Degre S, Sergysels R, Messin R et al. Hemodynamic responses to physical training in patients with chronic lung disease. Am Rev Respir Dis 1974; 110: 395-402.

15 McGavin CR, Gupta SP, Lloyd EL, McHardy GJR. Physical rehabilitation for the chronic bronchitic: results of a controlled trial of exercises in the home. Thorax 1977; 32: 307-11.

16 Sergysels R, DeCoster A, Degre S, Denolin H. Functional evaluation of a physical rehabilitation program including breathing exercises and bicycle training in chronic obstructive lung disease. Respiration 1979; 38: 105-11.

17 Mertens DJ, Shephard RJ, Kavanagh T. Long-term exercise therapy for chronic obstructive lung disease. Respiration 1978; 35: 96-107.

18 Sinclair DJM, Ingram CG. Controlled trial of supervised exercise training in chronic bronchitis. Br Med J 1980; 280: 519-21.

19 White SJ, Freedman LS. Allocation of patients to treatment groups in a controlled clinical study. Br J Cancer 1978: 37: 849-57.

20 McGavin CR, Gupta SP, McHardy GJR. Twelveminute walking test for assessing disability in chronic bronchitis. Br Med J 1976; 1: 822-3.

21 McDermott M, McDermott TJ. Digital incremental techniques applied to spirometry. Proc $R$ Soc Med 1977; 70: $169-71$.

22 Cotes JE. Response to progressive exercise: a threeindex test. Br J Dis Chest 1972; 66: 169-83.

23 Bassey EJ, Fentem PH, MacDonald IC, Scriven PM. Self-paced walking as a method for exercise testing in elderly and young men. Clin Sci Mol Med $1976^{\circ}$ 51: 609-12. 